\title{
Research on Archives Communication in the New Media Age
}

\author{
Chen Lei \\ Coal Economy Academy \\ Shandong Institute of Business and Technology \\ Yan Tai, China \\ chen177@163.com
}

\author{
Chen Shuying \\ Key Laboratory of Intelligent Information Processing in \\ Universities of Shandong \\ Shandong Institute of Business and Technology \\ Yan Tai, China \\ 304779566@qq.com
}

\begin{abstract}
In the era of new media, the dissemination of archival information should conform to the trend of the times. It should make use of the influence of new media, improve the cognitive ability and sense of archives of the public, and use new media to expand the dissemination of Archives. Through the network investigation, we find out the new forms of new media communication, they are the Internet, community interaction and mobile terminal. Through the research, we find that there are still problems in the dissemination of archives in the new media field, such as the lack of digital archives, the lack of publicity and the backwardness of the thinking and technology of Archivists. In view of the above problems, the paper puts forward an improved method of archives communication under the form of new media. On the basis of fully drawing on the advanced experience of other countries, the new media archives data center will be established, and the intelligent inspection technology will be improved and the experience of the users will be increased. In the interactive visualization environment, the new media dissemination of archives will achieve good results.
\end{abstract}

Keywords—new media; archives; forms of communication; website; mobile phone app

\section{INTRODUCTION}

With the continuous improvement of information technology and the wide application of network technology, new media has been widely used in every aspect. New media is relying on Internet technology to develop new media forms, including network media, mobile media, digital TV and so on. The new media is a broad concept, the use of digital technology, network technology, through the Internet, broadband LAN, wireless communication network, satellite channels, and computer, mobile phone, digital TV and other forms of communication terminal, providing information and entertainment services to users. New media has changed the mode of information transmission in traditional media. In the model, it changes the direction of the media in the past. The new media has brought about a profound impact on society as a whole, and also brought new opportunities for the dissemination of Archives. Traditional media is mainly reflected in newspapers, radio and so on. Now, people are mainly using the network as the main body for information dissemination and utilization, and people love and support this way. The dissemination and utilization of archives are no exception. Archivists can make use of new media's immediacy, interactivity, massive information and other great advantages, send the archives information to others at any time. In this way, people can read all kinds of archival information in time, through mobile phones, We Chat, micro-blog and so on, and they can communicate with each other.

The existence of new media makes the archival information break the space and time limit, greatly reducing the storage and storage costs. It avoids the loss of archives caused by too long time, and also provides a convenient channel for the widespread dissemination and utilization. In this context, the integration of archival information and new media has become increasingly evident, and the mode of transmission of archival information has been changing constantly. Especially after the emergence of new media, the dissemination and utilization of archival information based on new media has entered a new era, while the mode of communication is constantly innovating, the excavation and utilization of archives value has been promoted to a new height.

\section{ADVANTAGES OF ARCHIVAL COMMUNICATION IN THE FORM OF NEW MEDIA}

\section{A. The new media will help improve the public's cognitive ability in Archives}

For a long time, the archives work pays attention to the custody, despises the utilization, and makes the archives far from the sight of the ordinary people. Many archives administration departments are cumbersome in their procedures and inconvenient in their use. With the promotion of service oriented government, the service function of archives has been highlighted, and more people begin to use archives in their daily life. New media has opened up new channels and promoted the use and sharing of archives resources. For example, the opening of the archival WeChat public number, archival micro-blog, archival portals and so on Archival users can realize online inquiry archives, obtain relevant information of archives and feedback relevant questions. At the same time, people can also upload file resources through new media to realize the sharing of archives information resources. The extensive application of new 
media in the field of archives makes people have a deeper understanding of the value of archives, and directly or indirectly improves the public's cognitive ability in Archives.

\section{B. New media is good for archival propaganda}

New media is an open platform based on the internet. There is more room for the use and dissemination of archives, and it is selective in time. The multi-directional interaction of new media makes archives dissemination more personalized and diverse, and enhances the applicability of new media in different environments. In the new media age, people's archival demand has changed imperceptibly. People want to get as much archival information as possible in the shortest possible time. For archival communicators, you can promote archival information by WeChat, micro-blog and social media platforms. Information dissemination is not only convenient, but also diverse. It improves the propaganda efficiency. For archival recipients, only by computer, portable devices, mobile phones can receive archival information in a timely manner, but also in accordance with their own circumstances to choose any time to read.

The new media has greatly expanded the propaganda channels of archives. The traditional archives propaganda mainly depends on holding special archives exhibitions, publishing paper archives, newspapers and periodicals, publishing archives, compiling and researching achievements, and making archives and TV programs. New media can use more abundant forms to promote archival information. It has the characteristics of timeliness and interactivity, it can also timely and in accordance with social hot spots and public demand, timely and targeted dissemination of file information. This effectively makes up for the simplicity and hysteresis of traditional archival propaganda.

\section{New media will help improve public awareness of Archives}

There are many reasons for the low consciousness of public archives, For example, the use of channels is relatively simple, insufficient attention to archives, the means of management are not scientific enough, the degree of opening is not high enough, and the publicity of archives is not enough. Propaganda is not enough, is a very important reason, for a long period of time, the work of archives pays too much attention to confidentiality, but there is not enough effort to publicize the knowledge, value and utilization channels of Archives. After the promulgation and implementation of the archives law of the People's Republic of China. Although the archival publicity intensified, and achieved better social results, there is a single form of publicity, and less publicity of value. These limit the enhancement of public archives consciousness.

The new media has expanded the scope of archival publicity. Archival management department opened WeChat public number, the official micro-blog, etc., all people can pay attention to. This allows archival information to be acquired by more people without limitation of time and place. New media provide diversified choices for the form and content of archives publicity. It can provide a variety of content, close to the life of the file publicity. It can also bring new experiences to people's work, study and entertainment. So as to enhance the awareness of public archives to create a good atmosphere for publicity.

\section{THE FORM OF NEW MEDIA FOR ARCHIVAL INFORMATION}

\section{A. The Internet is an important form of new media for archival information}

As of December 2016, China's Internet users reached 731 million, a total of 42 million 990 thousand new Internet users throughout the year. The Internet penetration rate was $53.2 \%$, up 2.9 percentage points from the end of 2015. Mobile terminal applications become the main force. As of December 2016, Mobile phone users in China reached 695 million, an increase of 5 million 500 thousand compared with the end of 2015, Internet users use the mobile phone online crowd accounted for $90.1 \%$ from 2015 to $95.1 \%$, an increase of 5 percentage points, The percentage of Internet users on mobile phones has climbed further on a high base. China's mobile phone is expected to reach 739 million in 2017, and the proportion of Internet users using mobile phones will increase from $95.1 \%$ in 2016 to $97.8 \%$ [1]

On-demand access is a major feature of the Internet age, with the expansion of Internet users, the use of archives information on the Internet has been increasing. This communication has broken the limitations of traditional media, it is convenient, quick and profound. Whether academic researchers in the field of expertise or students who seek knowledge, even the public who is curious about the history archives, they can find the required files accurately on the Internet in a relatively short period of time, which greatly improves the efficiency of file utilization. Especially the openness of the Internet, the maximum extent of archival information to the audience in the form of the original ecology, which further promote the discovery of the potential value of archival information.

\section{B. Social interaction is the backbone of the dissemination of Internet archival information}

The dissemination of archival information based on traditional media has a significant unidirectional nature. The audience passively receives information and lacks feedback. The main mode of archival communication adopts such oneway process as "the joint production of media and archives keeping units - media release and audience acceptance", the problem is that the front end does not grasp the demand of the backend, which leads to the lack of information dissemination or narrow audience. Under the new media platform, the mode of file communication is changed from passive reception to active choice, the work effect of the archives keeping unit can be feedback and improved in a short time to form a positive feedback cycle. This interaction is also an important feature of the Internet media platform, whether the "reply", "comment", "forwarding" and other functions development, or is based on SNS platform of social modules widely used, reflects its interaction characteristics different from traditional media [2]. The existence of interactivity plays an amplification role in the dissemination of archival information on the one hand, in the society in a short period of time to form a "rave reviews" or "universally condemned" phenomenon, to some extent, the 
effect and influence of communication will be realized in an explosive fashion; On the other hand, interactivity can realize the effect of "truth", "debate" and "clearer", namely, to achieve the scientific popularization of archival information in the form of approximate interactive teaching, and to realize the value realization of Archives.

\section{Mobile Internet media is a new force in the dissemination of archival information}

Mobile Internet, that is, mobile communications and the Internet combine to become one of the two, refers to the Internet technology, platforms, business models and applications, and mobile communications technology combined with the practice of the general term. Mobile Internet applications are mainly smart phones, tablet PCs or other smart wearable devices. Its characteristic is to satisfy people's demand for information interaction at any time, in any space. Mobile Internet has occupied the time of people's fragmentation, so it has a wider audience, Such as micro-blog, WeChat and other software widespread application reflects the influence of the mobile Internet. Archives information storage units can be spread through micro-blog or other platform applications, or through the self-built APP application software, directly access to the audience's terminal.

\section{PROBLEMS IN THE DISSEMINATION OF ARCHIVAL INFORMATION FROM THE PERSPECTIVE OF NEW MEDIA}

\section{A. Lack of digitalization}

In the background of social informatization, many archives management organizations in China are actively promoting the reform of digital archives, and for this purpose, many websites and online archives have been built, it provides an excellent platform for better dissemination and use of archives information. Users can find what they need more easily and accurately. But there are still many shortcomings [3]. The current archival organization website production is poor, the layout of the page is not beautiful, lack of humanity, content is simple, information update is not timely, retrieval is not accurate, the server is poor, cannot give users a good experience. The file information management system is not mature enough, the retrieval mode is single, and it cannot be humanized, and cannot be freely and independently retrieved, thus affecting the efficiency of the use of electronic records.

\section{B. Propaganda is not enough}

Publicity is inappropriate and it is difficult for the public to understand the site and the site does not have enough access. Leaders at all levels do not pay enough attention to it, regard the information communication platform as unimportant construction, the archives informatization and website construction have not been paid attention to, not getting enough manpower or financial support.

\section{Archivists' Ideological and technical backwardness}

In recent years, the scientific and cultural level of Chinese Archives practitioners has improved, but compared to other industries, there is still no small gap. Especially for computer technology and new media technology understanding, application ability is poor, can't keep up with the speed of progress of the times. There is not enough talented people to build it. It's a big problem in the progress of Digital Archives [4]. Many practitioners feel more difficult to learn, so that some people have a fear. This is also one of the reasons why it is hard for the archives industry to make progress in digital construction.

\section{Management is not standard}

As each media operates differently, its conditions and management are different. The media management departments lack overall consideration for the development, layout and management ability of archives management. It is far from forming the industry standard and operating procedures applicable to the new media age.

\section{THE IMPROVEMENT OF FILE COMMUNICATION UNDER THE FORM OF NEW MEDIA}

Combined with the actual development of archives, in order to promote the large-scale development of archives communication, we propose the following suggestions.

\section{A. Make full use of the advanced experience of other countries and revise and perfect the current management mode}

We must change the closed service system and concept. For example, the United States on social networking archives of media exploration is a good example. The archives department in America has formed a management pattern of "three changes and one characteristic" in management. That is, the systematization of institutional framework, the informationization of management means, the legalization of safeguard measures and the characteristics of high openness [5]. In 2012, the social media Archive Platform in North Carolina was the world's first public platform for archiving social media data and metadata. The incident became the first test of archival management of social media data, drawing widespread attention from social networking and Archival Science. At the end of 2012, the Twitter website launched a new feature to provide users with complete archive. The user may obtain relevant information after selecting the scope and application of the required filing. At the same time, Tw it $t$ e $r$ website also upgraded the search function, easy for the first time to find relevant information. In October 20, 2011, the National Archives and document administration released the guidelines for document management guidelines for Web 2.0 and social media platforms. The guide manages archives generated by social media platforms. Although a variety of new media, but the current file management is concentrated in the Facebook and Twitter file management, because the two platforms have the most users and the most active, the accumulation of data and information is also the most concentrated and valuable. The relevant practices of the United States deserve our attention and research, and it has positive significance for the management of archives in the new media age. 


\section{B. Establish a new media archive data center}

At present, the hardware construction is undoubtedly the weak link. Data is the core resource of file service. We need a large amount of business data, user data and semantic data, on this basis, the information resources are developed and processed, such as data integration, data storage, information analysis, query processing, distributed index and interactive data visualization. Internet data belongs to chaotic data and is in an unclassified state. Using the latest clustering algorithm, the archives can be automatically grouped according to time, character, location, subject and so on. It can be aggregated into different data sets. Next, the association analysis is performed on the data set, association analysis is the basis of archives management, and also the basis of Archival Service. Only high-quality archives information can meet the needs of users and realize the value of Archives.

\section{Intelligent retrieval technology}

Retrieval is the most basic file service. Under the new technical conditions, there has been a new breakthrough in archival retrieval, which is embodied in the enhancement of intelligence. As far as foreign countries are concerned, archives retrieval has been completely automated and intelligent, for example, it provides multi field retrieval, keyword search, progressive search and cloud retrieval [6]. After the retrieval, the visualization technique can give the user a concise answer. In the Web 3.0 environment, the performance of visualization technology has been improved qualitatively. Information feedback from a single graphic form across to a stereoscopic form, for example, aggregate audio, video, 30 visual effects, etc. Visualization technology is moving toward intelligent and interactive directions, In interactive visualization technology, users are not only recipients of information, but also producers of visual information, That is, the user makes visual information according to his own interests and shares the information to other users in the same network.

\section{CONCLUSION}

Archives digitization is a new kind of archival management mode which is produced with the development of information technology. Digital archives have great advantages over the traditional way in the collection, collation, storage, dissemination, statistics and retrieval of Archives. The use of new media technology is the current trend, but also better program. We should look at the issue in a new light, at the forefront of science and technology, to carry out all staff to learn new knowledge, new technologies, improve service levels, and keep pace with the new media era. Through the establishment of Web sites, micro-blog, WeChat, mobile phones, APP and so on, to meet everyone at home can also read and find archives anytime and anywhere, so that people enjoy a better new experience. The transformation and utilization of archives in the new media era is not a fable. We should change the past monotonous and stationary documents to provide the means of utilization, and provide users with integrated information processing and utilization services such as graphics, text, sound and image. In the full use of new media technology conditions, improve the efficiency of the use of archives, in order to improve social resources utilization.

\section{REFERENCES}

[1] China Internet Network Information Center http://www.cnnic.net.cn/hlwfzyj/hlwxzbg/hlwtjbg/201701/t20170122_6 6437.htm. (In Chinese)

[2] Xia Qing. Archives management of media industry in new media times [J] Chinese archives, 2015 (2): 75. (In Chinese)

[3] Dai Zhongqiu, Zhao Ningyan. Data management $J$ in the construction of archives informatization. Archives and management, 2012 (3): 23-25. (In Chinese)

[4] Zhang Shuguang. All media from the perspective of social function of archives on [J]. Lantai world, 2015, (2). (In Chinese)

[5] Zhang Xin, Xu Ke, Hu Minghao. New media and Archives Culture Research [J]. Shanghai archives, 2014, (11). (In Chinese)

[6] chinanews.com. Ministry of industry: the scale of China's mobile Internet users nearly 900 million [EB/OL].[2015-421]http://www.ce.cn/cysc/tech/07hlw/guonei/201504/17/t20150417_514 1397.shtml. (In Chinese) 